\title{
Oxygenation With a Single Portable Pulse-Dose Oxygen-Conserving Device and Combined Stationary and Portable Oxygen Delivery Devices in Subjects With COPD
}

\author{
Aina M Yáñez PhD, Jose P Prat MSc, José L Álvarez-Sala PhD MD, Myriam Calle MD, \\ Salvador Díaz Lobato PhD MD, José L García Gonzalez, \\ José M Rodríguez Gonzalez-Moro PhD MD, Raul Galera-Martínez MD, Carlos Villasante MD, \\ Inmaculada Ramos MD, Mercedes Franco-Gay MSc, and Pilar de Lucas PhD MD
}

\begin{abstract}
BACKGROUND: Portable oxygen devices simplify and facilitate patient therapy. This study was designed to compare $\mathrm{S}_{\mathrm{pO}_{2}}$ and patient satisfaction with a portable oxygen concentrator or a combined system consisting of a fixed device with continuous-flow oxygen dispensation and a portable device with pulse dispensation for ambulation. METHODS: This crossover trial assessed 25 subjects with COPD (92\% men, mean age of $72.2 \pm 7.4 \mathrm{y}$, mean $\mathrm{FEV}_{1}$ of $34.14 \pm 12.51 \%$ of predicted) at 4 hospitals in Madrid. All subjects had previously used the combined system, consisting of a fixed oxygenation system and a portable system for ambulation, with $16(64 \%)$ using stationary and portable concentrators and $9(36 \%)$ using a stationary reservoir and portable liquid oxygen bag. Oxygenation settings at rest and while walking were determined at baseline. Subjects were maintained on the previous combined system for 1 week and then switched to the portable oxygen concentrator for 1 week. Mean $\mathrm{S}_{\mathrm{pO}_{2}}$ over $24 \mathrm{~h}$ was calculated using the software in the oximeter, and compliance was monitored (Visionox). RESULTS: Low $\mathrm{S}_{\mathrm{pO}_{2}}(<90 \%)$ was significantly more frequent during use of the portable concentrator alone than with the combined system $(37.1 \%$ vs $18.4 \%, P<.05)$. The portable system alone was preferred by $43 \%$ of subjects, and the combined system was preferred by $36 \%$, whereas $21 \%$ were not sure. CONCLUSIONS: Subjects preferred using a single portable oxygenation system both at home and during ambulation. Portable systems alone, however, did not supply the same levels of oxygenation as the combination of fixed and portable systems. Before the widespread adoption of portable systems as a single device, additional studies are needed to determine best-practice protocols for adjustment of daytime and nighttime oxygenation settings. (ClinicalTrials.gov registration NCT02079753) Key words: COPD; chronic respiratory failure; portable concentrator; oxygen sources; oxygen concentrator; ambulation. [Respir Care 2015;60(3):382-387. (c) 2015 Daedalus Enterprises]
\end{abstract}

\section{Introduction}

Long-term oxygen therapy has been found to reduce morbidity and mortality rates and to improve health-re-

Dr Yáñez is affiliated with the Instituto de Investigación Sanitaria de Palma (IdISPa), Palma de Mallorca, Spain. Mr Prat, Dr Ramos, and Ms Franco-Gay are affiliated with Linde Healthcare (Linde Médica), Madrid, Spain. Drs Álvarez-Sala and Calle are affiliated with the Servicio de Neumología, Hospital Clínico de San Carlos, Facultad de Medicina, Universidad Complutense de Madrid, Madrid, Spain. Dr Díaz Lobato and $\mathrm{Mr}$ Gonzalez are affiliated with the Servicio de Neumología, Hospital Universitario Ramón y Cajal, Madrid, Spain. Drs Gonzalez-Moro and de Lucas are affiliated with the Servicio de Neumología, Hospital General lated quality of life in patients with COPD and chronic respiratory failure. ${ }^{1-4}$ Although ambulatory oxygen has not been found to improve mortality rates, it has been shown to increase exercise tolerance ${ }^{5}$ and compliance with oxygen therapy. ${ }^{6}$

\footnotetext{
Universitario Gregorio Marañón, Madrid, Spain. Drs Galera-Martínez and Villasante are affiliated with the Servicio de Neumología, Hospital Universitario La Paz, Instituto de Investigación Hospital Universitario La Paz (IdiPAZ), Madrid, Spain.

This study was supported by Linde Healthcare (Linde Médica, Madrid, Spain). The authors have disclosed no other conflicts of interest.
} 


\section{Oxygenation in Subjects With COPD}

One of the most used oxygen-conserving devices is pulsedose technology, also referred to as demand oxygen delivery systems. These portable long-term oxygen therapy systems provide patients with greater autonomy by reducing the consumption of oxygen from the source. However, selecting the most appropriate $\mathrm{O}_{2}$ source depends on both the characteristics of individual patients and the properties of the oxygen sources. ${ }^{7}$ For example, oxygen-conserving devices that use pulse-dose technology generally maintain adequate daytime and nighttime oxygenation, ${ }^{8,9}$ but may be less efficient during periods of exercise and elevated breathing frequencies. ${ }^{10}$

Oxygen-conserving devices using demand oxygen delivery require 2 sources, a stationary source and a portable source. ${ }^{11}$ However, although such systems are more efficient, they are also more costly. A dual-use device, consisting of a portable device that can also be used at home, would simplify ambulation, reduce costs, and facilitate patient therapy. This study was therefore designed to compare oxygenation and patient satisfaction during use of a portable pulse-dose oxygen concentrator compared with a combined system consisting of a fixed device with continuous-flow oxygen dispensation and a portable device with pulse dispensation for ambulation.

\section{Methods}

This open, multi-center, crossover trial was performed at 4 university hospitals in the Madrid region: Hospital General Universitario Gregorio Marañón, Hospital Clínico de San Carlos, Hospital Universitario Ramón y Cajal, and Hospital Universitario La Paz. All subjects had been diagnosed with COPD and were using both stationary (an oxygen concentrator or a liquid oxygen reservoir with continuous-flow oxygen delivery) and portable (a portable liquid oxygen bag or portable concentrator with pulsedose technology) oxygen delivery devices.

Subjects were included if they were $40-80$ y of age, had been diagnosed with COPD following the Global Initiative for Chronic Obstructive Lung Disease (GOLD) criteria, ${ }^{12}$ were receiving oxygen therapy for daytime hypoxemia, were using a fixed oxygenation system and a portable system for ambulation, were without exacerbation during the previous month, and agreed to participate. Subjects were excluded if they were terminally ill, were unable to understand Spanish, had a high oxygen flow at rest $(>3$ $\mathrm{L} / \mathrm{min})$, had a high breathing frequency at rest $(>32$

Correspondence: Aina M Yáñez PhD, Instituto de Investigación Sanitaria de Palma (IdISPa), Carretera de Valldemossa 79, 07120 Palma de Mallorca, Islas Baleares, Spain. E-mail: ainam.yanez@ssib.es.

DOI: $10.4187 /$ respcare. 03470

\section{QUICK LOOK}

\section{Current knowledge}

Portable oxygen systems are designed to alleviate hypoxemia at rest and during activity. In the United States, home oxygen therapy is most frequently supplied by a portable concentrator. The ability of a concentrator to meet patient demands with activity is variable.

\section{What this paper contributes to our knowledge}

Subjects preferred a single portable oxygen concentrator versus a combined system at home and during activity. However, hypoxemia was more frequent with a single device. A combined system was able to reduce the incidence of hypoxemic events.

breaths/min), were not achieving adequate $\mathrm{S}_{\mathrm{pO}_{2}}$ levels during titration with the portable oxygen source, had previously been diagnosed with obstructive sleep apnea-hypopnea syndrome, or were receiving mechanical ventilation. The study was approved by the Ethical Investigation Committee of the Clinical Region of the Madrid Community (CEIC 06/11). All subjects gave written informed consent.

Subjects were recruited from pneumology services after searching the hospital databases for patients receiving ambulatory oxygen therapy. Following preselection, the subjects were visited at the hospital (run-in visit) to collect sociodemographic and clinical data and to determine and adjust the oxygenation settings of each device, both at rest and while walking. Each session began with the subject breathing room air for 30 min, after which $\mathrm{S}_{\mathrm{pO}_{2}}$ was recorded. The resting oxygen flow was adjusted based on previous arterial blood gas analysis. This flow was confirmed while monitoring oximetry such that the subject maintained $\mathrm{S}_{\mathrm{pO}_{2}}$ at $\geq 92 \%$ for at least $2 \mathrm{~min}$; if $\mathrm{S}_{\mathrm{pO}_{2}}$ was lower, the flow level/setting was increased. To determine the ambulatory oxygen setting, subjects were asked to walk at their normal pace at the resting oxygen flow. $\mathrm{S}_{\mathrm{pO}_{2}}$ was measured every $30-60 \mathrm{~s}$; if it was $<92 \%$, the flow was increased until an $\mathrm{S}_{\mathrm{pO}_{2}}$ of at least $92 \%$ was maintained for at least 2 min during physical activity.

During the run-in period, subjects who had not undergone a sleep apnea study within the previous year were monitored for sleep apnea in their homes (Alice PDx polygraph, Philips Respironics, Murrysville, Pennsylvania). Subjects with obstructive sleep apnea, defined as an apnea index of $>20$, were excluded from the study.

After the run-in period (1-4 weeks), each subject was visited 4 times at home by a technician trained in oxygen therapy. During the first visit, the technician installed a 


\section{Oxygenation in Subjects With COPD}

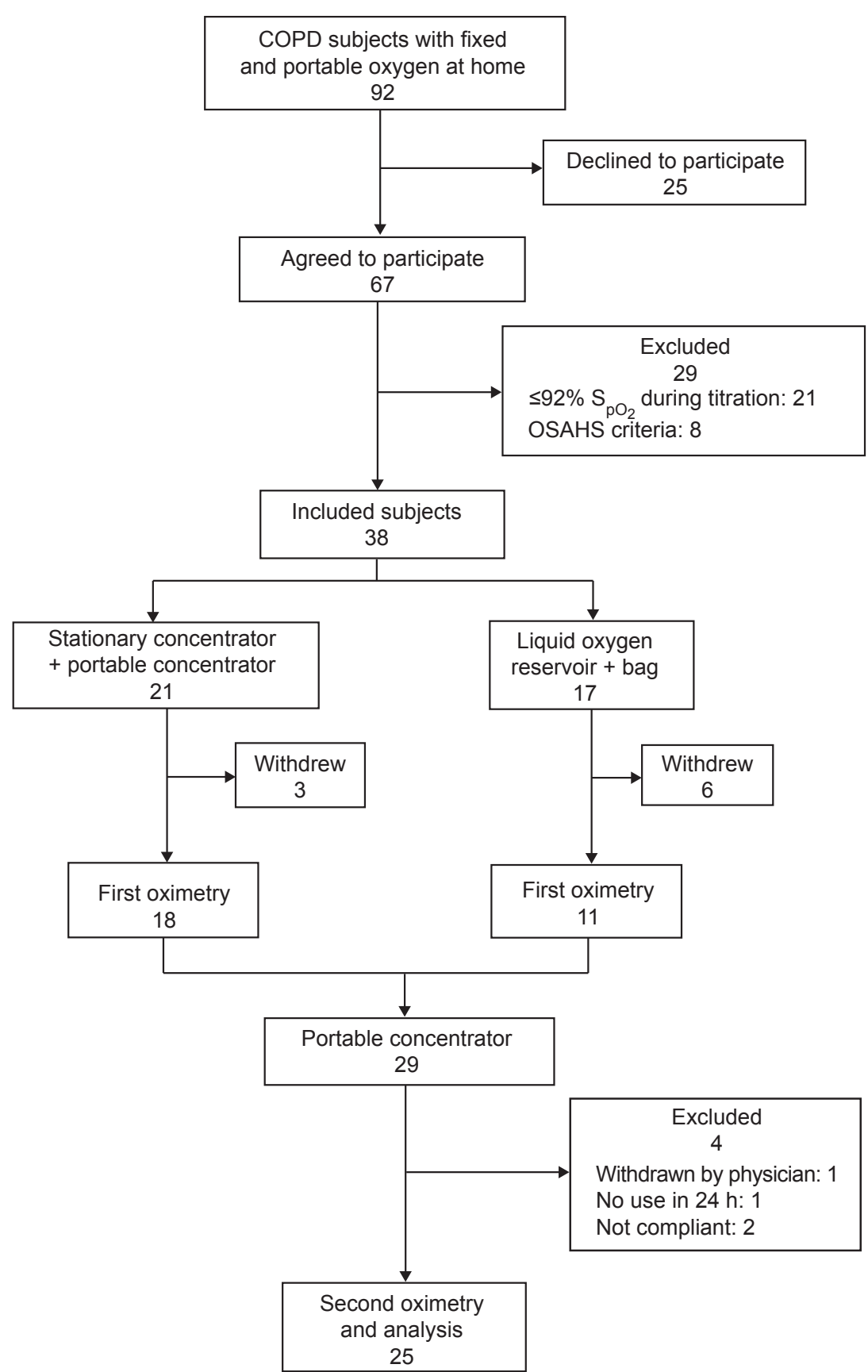

Fig. 1. Flow chart. OSAHS = obstructive sleep apnea-hypopnea syndrome.

reservoir of liquid oxygen (Liberator 30, Caire Medical, Ball Ground, Georgia) and a liquid Stroller oxygen pack (Caire Medical) for subjects using liquid oxygen or a VisionAire 5 stationary concentrator (AirSep, Buffalo, New York) and an Inogen One G2 portable concentrator (Inogen, Goleta, California) for subjects using concentrators. An electronic compliance monitor (Visionox, Madrid, Spain) ${ }^{13}$ was installed in each device. Proper operation of these devices was also verified during this visit.
During the second visit, performed 6-8 d later (adaptation period), a pulse oximeter (WristOx2, Nonin, Plymouth, Minnesota) was placed on the finger of each subject for $24 \mathrm{~h}$ to measure oxygenation when using oxygen devices. Each subject was also given a 24-h self-register sheet to record physical activities performed, use of each oxygen delivery device, and the time each patient went to bed and awoke over a $24-\mathrm{h}$ period. During the third visit, performed $1 \mathrm{~d}$ after the second visit, the oximeter was 


\section{Oxygenation in Subjects With COPD}

removed, and an Inogen One G2 portable concentrator was installed and its operation verified. During the fourth visit, performed 6-8 d after the third visit (adaptation period), a pulse oximeter was again installed, and a 24-h register was given to the subject, as during the second visit.

Before the second and fourth visits, each subject was surveyed by telephone to assess the opinion of the systems, including convenience of use. During the last call, subjects were also asked about their preferences.

The data obtained from the oximeter, compliance monitor, and registers were evaluated and synchronized. The pulse oximeter and each compliance monitor have an internal clock, and all data recorded in these devices include date and time. The 24-h register also included date and time of use of each oxygen delivery device, as well as the time the subject went to bed. Because there was a time reference in all 3 registers, we could synchronize all the information obtained. Only the segments from the oximetry record corresponding to the time of use of the respective oxygen devices were classified according to their use. The subject register was used to codify nighttime and daytime. For each subject and oxygen system, the following parameters were calculated: hours/d used, average $\mathrm{S}_{\mathrm{pO}_{2}}$, and percentages of time with $\mathrm{S}_{\mathrm{pO}_{2}}<90 \%$ and $\mathrm{S}_{\mathrm{pO}_{2}}<88 \%$.

The main dependent variable was the percentage of time spent desaturated below $90 \%$ when using a specific system. A $t$ test for repeated measurements was performed to compare percentages of time spent desaturated below $90 \%$ and $88 \%$.

\section{Results}

Between June 2011 and February 2012, 67 subjects were identified, but 29 were excluded, including 21 subjects who did not reach adequate $\mathrm{S}_{\mathrm{pO}_{2}}$ levels during titration with the portable oxygen source while ambulating and 8 subjects with obstructive sleep apnea-hypopnea syndrome.

Of the remaining 38 subjects, 13 were lost to follow-up: 9 subjects withdrew consent, one subject was switched from the single system to the combined system by his physician, 2 subjects had inaccurate compliance monitor registers, and one subject did not use the portable concentrator in the final evaluation (Fig. 1).

Twenty-five subjects were finally evaluated. Table 1 shows their clinical and demographic characteristics at baseline. Mean subject age was $72.2 \pm 7.4 \mathrm{y}$, and 23 $(92 \%)$ were male. At baseline, 16 subjects $(64 \%)$ used stationary and portable concentrators, and 9 subjects (36\%) used a reservoir and liquid oxygen bag.

The percentage of time that subjects remained at low $\mathrm{S}_{\mathrm{pO}_{2}}(<90 \%)$ was significantly greater when using the portable concentrator alone than when using the combined system $(37.1 \%$ vs $18.4 \%, P<.05)$. There were no differences during the entire 24-h period or during daytime or
Table 1. Demographic and Clinical Characteristics of the 25 Studied Subjects

\begin{tabular}{|c|c|}
\hline Characteristics & Values \\
\hline \multicolumn{2}{|l|}{ Gender, $n(\%)$} \\
\hline Female & $2(8)$ \\
\hline Male & $23(92)$ \\
\hline Age (mean $\pm S D), y$ & $72.2 \pm 7.4$ \\
\hline Years since diagnosis of COPD $($ mean $\pm \mathrm{SD})$ & $6.04 \pm 3.98$ \\
\hline $\mathrm{FEV}_{1}($ mean $\pm \mathrm{SD}), \mathrm{L}$ & $0.96 \pm 0.30$ \\
\hline $\mathrm{FEV}_{1}($ mean $\pm \mathrm{SD}) \%$ of predicted & $34.14 \pm 12.51$ \\
\hline $\mathrm{FVC}($ mean $\pm \mathrm{SD}), \mathrm{L}$ & $1.93 \pm 0.59$ \\
\hline FVC (mean $\pm \mathrm{SD}), \%$ of predicted & $49.23 \pm 13.67$ \\
\hline $\mathrm{FEV}_{1} / \mathrm{FVC}($ mean $\pm \mathrm{SD})$ & $0.51 \pm 0.12$ \\
\hline $\mathrm{S}_{\mathrm{pO}_{2}}$ at rest without oxygen therapy, $\%$ & $89 \pm 2$ \\
\hline \multicolumn{2}{|l|}{ Devices used before inclusion } \\
\hline $\begin{array}{l}\text { Stationary concentrator and portable } \\
\text { concentrator, } n(\%)\end{array}$ & $16(64)$ \\
\hline Liquid oxygen and liquid oxygen bag, $n(\%)$ & $9(36)$ \\
\hline
\end{tabular}

nighttime between subjects using the combined stationary and portable oxygen concentrators and those using reservoirs and liquid oxygen bags (Table 2). The percentage of nighttime spent at $\mathrm{S}_{\mathrm{pO}_{2}}<90 \%$ was significantly greater when using the portable concentrator alone than when using the combined system $(44.3 \%$ vs $13.4 \%, P<.05)$. During daylight hours, however, the difference was not statistically significant $(30.1 \%$ vs $22.5 \%, P=.12$; data not shown).

Subject survey results are shown in Table 3 . We found that $43 \%$ of subjects preferred the portable system as a single oxygen delivery device, $36 \%$ preferred the combined portable and stationary devices, and $21 \%$ had no preference. Of the 11 subjects using liquid oxygen (reservoir and bag), 5 subjects (45\%) regarded the single system as providing greater autonomy and comfort, and 2 subjects (18\%) regarded the single system as more practical than their previous system. Five subjects (45\%) mentioned that the main disadvantage of this device was noise. Of the 17 subjects who had previously used oxygen concentrators (stationary and portable), 10 subjects (59\%) found that the main advantage of the single system was its greater practicality, and 3 subjects (18\%) reported that the main disadvantage was noise.

\section{Discussion}

The results presented here indicate that subjects on a single pulse-dose concentrator device remain at a lower $\mathrm{S}_{\mathrm{pO}_{2}}$ than when using a combination system of a portable and a stationary device, especially at night. Our survey found, however, that more subjects preferred a single system over 2 devices. Use of a portable system alone can 


\section{Oxygenation in Subjects With COPD}

Table 2. $\mathrm{S}_{\mathrm{pO}_{2}}$ Using a Portable Oxygenation System for the Entire Day or Using Fixed and Portable Systems

\begin{tabular}{|c|c|c|c|c|c|c|}
\hline & \multicolumn{2}{|c|}{$\begin{array}{l}\text { Subjects With Concentrators } \\
\qquad(n=16)\end{array}$} & \multicolumn{2}{|c|}{$\begin{array}{l}\text { Subjects With Liquid Oxygen } \\
\qquad(n=9)\end{array}$} & \multicolumn{2}{|c|}{$\begin{array}{l}\text { Total Subjects } \\
\quad(N=25)\end{array}$} \\
\hline & $\begin{array}{l}\text { Fixed }+ \text { Portable } \\
\quad(\text { Mean } \pm \text { SD })\end{array}$ & $\begin{array}{c}\text { Portable } \\
(\text { Mean } \pm \text { SD) }\end{array}$ & $\begin{array}{c}\text { Stationary } \\
\text { Liquid Oxygen }+ \text { Bag } \\
(\text { Mean } \pm \text { SD) }\end{array}$ & $\begin{array}{c}\text { Portable } \\
(\text { Mean } \pm \mathrm{SD})\end{array}$ & $\begin{array}{l}\text { Fixed + Portable } \\
\quad(\text { Mean } \pm \text { SD })\end{array}$ & $\begin{array}{c}\text { Portable } \\
(\text { Mean } \pm \text { SD })\end{array}$ \\
\hline Duration of use, $\mathrm{h} / \mathrm{d}$ & $15.6 \pm 7.1$ & $11.2 \pm 5.2$ & $11.8 \pm 5.7$ & $13.9 \pm 6.0$ & $14.2 \pm 6.7$ & $12.1 \pm 5.5$ \\
\hline Mean $\mathrm{S}_{\mathrm{pO}_{2}}$ & $90.9 \pm 5.5$ & $89.7 \pm 3.4$ & $93.2 \pm 2.7$ & $90.3 \pm 6.0$ & $91.7 \pm 4.9$ & $89.8 \pm 4.5$ \\
\hline$\%$ time with $\mathrm{S}_{\mathrm{pO}_{2}}<90 \%$ & $18.8 \pm 15.2$ & $35.4 \pm 28.7^{*}$ & $17.8 \pm 17.7$ & $40.2 \pm 34.2$ & $18.4 \pm 15.8$ & $37.1 \pm 30.2^{*}$ \\
\hline$\%$ time with $\mathrm{S}_{\mathrm{pO}_{2}}<88 \%$ & $12.0 \pm 12.7$ & $32.0 \pm 34.6^{*}$ & $8.8 \pm 12.2$ & $29.1 \pm 36.4$ & $10.6 \pm 12.1$ & $29.8 \pm 34.2^{*}$ \\
\hline
\end{tabular}

Table 3. Results of the Subject Satisfaction Survey

\begin{tabular}{|c|c|c|c|c|c|c|}
\hline & \multicolumn{2}{|c|}{$\begin{array}{l}\text { Subjects With } \\
\text { Concentrators } \\
\quad(n=17)\end{array}$} & \multicolumn{2}{|c|}{$\begin{array}{l}\text { Subjects With } \\
\text { Liquid Oxygen } \\
\quad(n=11)\end{array}$} & \multicolumn{2}{|c|}{$\begin{array}{l}\text { Total Subjects } \\
\quad(N=28)\end{array}$} \\
\hline & $\begin{array}{c}\text { Fixed }+ \text { Portable, } \\
n(\%) \\
\end{array}$ & $\begin{array}{c}\text { Portable, } \\
n(\%)\end{array}$ & $\begin{array}{l}\text { Liquid Oxygen }+ \\
\text { Bag, } n(\%)\end{array}$ & $\begin{array}{c}\text { Portable, } \\
n(\%)\end{array}$ & $\begin{array}{c}\text { Fixed }+ \text { Portable, } \\
n(\%) \\
\end{array}$ & $\begin{array}{c}\text { Portable, } \\
n(\%)\end{array}$ \\
\hline \multicolumn{7}{|c|}{ How has the use of this oxygen system been? } \\
\hline Very easy & $5(29.4)$ & $2(11.8)$ & $4(36.4)$ & $3(27.3)$ & $9(32.1)$ & $5(17.9)$ \\
\hline Easy & $12(70.6)$ & $10(58.8)$ & $7(63.6)$ & $3(27.3)$ & $19(67.9)$ & $13(46.4)$ \\
\hline A bit complicated & $0(0)$ & $5(29.4)$ & $0(0)$ & $5(45.5)$ & $0(0)$ & $10(35.7)$ \\
\hline \multicolumn{7}{|c|}{ How has movement inside the house been? } \\
\hline Bad & $0(0)$ & $2(11.8)$ & $1(9.1)$ & $3(27.3)$ & $1(3.6)$ & $5(18.5)$ \\
\hline Neutral & $2(11.8)$ & $5(29.4)$ & $3(27.3)$ & $3(27.3)$ & $5(17.9)$ & $8(29.6)$ \\
\hline Good & $15(88.2)$ & $10(58.8)$ & $7(63.6)$ & $5(45.4)$ & $22(78.6)$ & $14(51.9)$ \\
\hline \multicolumn{7}{|c|}{ How has movement outside of the house been? } \\
\hline $\mathrm{Bad}$ & $0(0)$ & $0(0)$ & $1(9.1)$ & $2(18.2)$ & $1(3.6)$ & $2(7.1)$ \\
\hline Neutral & $1(5.9)$ & $2(11.8)$ & $1(9.1)$ & $0(0)$ & $2(7.1)$ & $2(7.1)$ \\
\hline Good & $9(52.9)$ & $8(47.0)$ & $7(63.6)$ & $4(36.4)$ & $16(57.1)$ & $12(42.9)$ \\
\hline Has not gone outside & $7(41.2)$ & $7(41.2)$ & $2(18.2)$ & $5(45.4)$ & $9(32.1)$ & $12(42.9)$ \\
\hline \multicolumn{7}{|c|}{$\begin{array}{l}\text { Have you stopped doing something to use } \\
\text { this system? }\end{array}$} \\
\hline Yes & $0(0)$ & $0(0)$ & $1(9.1)$ & $2(18.2)$ & $1(3.6)$ & $2(7.1)$ \\
\hline No & $17(100)$ & $17(100)$ & $10(90.9)$ & $9(81.8)$ & $27(96.4)$ & $26(92.9)$ \\
\hline \multicolumn{7}{|c|}{$\begin{array}{l}\text { How has it been complying with the No. of } \\
\text { hours of oxygen? }\end{array}$} \\
\hline Easy & $17(100)$ & $11(64.7)$ & $11(100)$ & $7(63.6)$ & $28(100)$ & $18(64.3)$ \\
\hline Neutral & $0(0)$ & $2(11.8)$ & $0(0)$ & $2(18.2)$ & $0(0)$ & $4(14.3)$ \\
\hline Complicated & $0(0)$ & $4(23.5)$ & $0(0)$ & $2(18.2)$ & $0(0)$ & $6(21.4)$ \\
\hline \multicolumn{7}{|c|}{ Which system would you keep? } \\
\hline Prefer portable + fixed & & $6(35.3)$ & & $4(36.4)$ & & $10(35.7)$ \\
\hline Prefer only the portable & & $8(47.0)$ & & $4(36.4)$ & & $12(42.9)$ \\
\hline Do not care & & $3(17.7)$ & & $3(27.3)$ & & $6(21.4)$ \\
\hline
\end{tabular}

Bag refers to the liquid oxygen portable system. More subjects were evaluated than for Table 2.

facilitate administration of treatment and can also lower therapeutic cost whenever appropriate levels of oxygenation are achieved.

A study comparing the efficacy of a pulse-dose system with a continuous-flow system in 15 subjects while exer- cising found that time spent at $\mathrm{S}_{\mathrm{pO}_{2}}<90 \%$ was greater with the pulse-dose device than with the continuous-flow system, suggesting that the efficiency of the pulse-dose system should be tested in subjects at rest and while exercising before its installation. ${ }^{14}$ 


\section{Oxygenation in Subjects With COPD}

Another study similar to ours compared oxygenation using a portable oxygen concentrator with pulse-dose technology and a continuous-flow stationary concentrator. ${ }^{9}$ Significant differences between these systems in mean $\mathrm{S}_{\mathrm{pO}_{2}}$ were observed (96\% vs 93\%), although they were regarded as clinically irrelevant because, in general, $\mathrm{S}_{\mathrm{pO}_{2}}$ did not fall below $90 \%$. In our study, the average $\mathrm{S}_{\mathrm{pO}_{2}}$ at night was lower when using both the continuous-flow and pulsedose systems than in the previous study, as was the percentage of time $\mathrm{S}_{\mathrm{pO}_{2}}$ was $\geq 90 \%$.

Another study that compared 4 devices with pulse-dose technology during exercise found that the saturation levels were very similar. ${ }^{15}$ However, that study was performed in a hospital setting and did not include a continuous-flow system as a control.

In our study, we applied a novel and pragmatic approach: the inclusion of subjects who required oxygen devices during ambulation and who were using a combination of a stationary and a portable system because these subjects are likely to be potential users of single portable systems. Furthermore, we standardized the titration of all oxygen sources, both at rest and while walking, to maximize the comparability of these systems and to ensure correct settings of each. Moreover, oximetry was performed over 24-h periods, mimicking a normal day in each subject's life. Furthermore, the compliance monitor was used to determine the oxygen device being used throughout the oximetry measurements.

The main limitation of our study was the small sample size of the study group. Although we observed statistically significant differences, studies with larger subject samples are needed to confirm our findings. Furthermore, the small sample size prevented us from assessing subject subgroups, such as those with severe hypoxia. Future studies evaluating the use of these portable systems at night should include titration and adjustment of settings for nighttime use. Moreover, this study excluded subjects with inadequate levels of oxygenation with the portable system during the titration period.

\section{Conclusions}

Our study suggests that the portable system was less effective than the combined stationary and portable devices over $24 \mathrm{~h}$. However, the portable system was more convenient and was preferred by subjects. Oxygen therapy should include a previous evaluation and titration of each patient with the device. Titration protocols for portable systems should include assessments during exercise, at rest, and while sleeping at night.

\section{REFERENCES}

1. Eaton T, Lewis C, Young P, Kennedy Y, Garrett JE, Kolbe J. Longterm oxygen therapy improves health-related quality of life. Respir Med 2004;98(4):285-293.

2. Nocturnal Oxygen Therapy Trial Group. Continuous or nocturnal oxygen therapy in hypoxemic chronic obstructive lung disease: a clinical trial. Ann Intern Med 1980;93(3):391-398.

3. Medical Research Council Working Party. Long-term domiciliary oxygen therapy in chronic hypoxic cor pulmonale complicating chronic bronchitis and emphysema. Lancet 1981;1(8222):681-686.

4. Ringbaek TJ, Viskum K, Lange P. Does long-term oxygen therapy reduce hospitalisation in hypoxaemic chronic obstructive pulmonary disease? Eur Respir J 2002;20(1):38-42.

5. Bradley JM, O'Neill B. Short-term ambulatory oxygen for chronic obstructive pulmonary disease. Cochrane Database Syst Rev 2005; (4):CD004356.

6. Ringbaek T, Lange P, Viskum K. Compliance with LTOT and consumption of mobile oxygen. Respir Med 1999;93(5):333-337.

7. Díaz Lobato S, Mayoralas Alises S. Mobility profiles of patients with home oxygen therapy. Arch Bronconeumol 2012;48(2):55-60.

8. Bower JS, Brook CJ, Zimmer K, Davis D. Performance of a demand oxygen saver system during rest, exercise, and sleep in hypoxemic patients. Chest 1988;94(1):77-80.

9. Chatburn RL, Lewarski JS, McCoy RW. Nocturnal oxygenation using a pulsed-dose oxygen-conserving device compared to continuous flow. Respir Care 2006;51(3):252-256.

10. Palwai A, Skowronski M, Coreno A, Drummond C, McFadden ER Jr. Critical comparisons of the clinical performance of oxygen-conserving devices. Am J Respir Crit Care Med 2010;181(10):10611071.

11. Castillo D, Güell R, Casan P. Oxygen-conserving devices: a forgotten resource. Arch Bronconeumol 2007;43(1):40-45.

12. Rabe KF, Hurd S, Anzueto A, Barnes PJ, Buist SA, Calverley P, et al. Global strategy for the diagnosis, management, and prevention of chronic obstructive pulmonary disease: GOLD executive summary. Am J Respir Crit Care Med 2007;176(6):532-555.

13. Pérez de Alejo R, Esteban R, Sacristán JC, Peces-Barba G. Monitor de cumplimiento de oxigenoterapia domiciliaria Visionox. Evaluación de eficacia y fiabilidad. Arch Bronconeumol 2009;45(Esp Congr):97.

14. Roberts CM, Bell J, Wedzicha JA. Comparison of the efficacy of a demand oxygen delivery system with continuous low flow oxygen in subjects with stable COPD and severe oxygen desaturation on walking. Thorax 1996;51(8):831-834.

15. Strickland SL, Hogan TM, Hogan RG, Sohal HS, McKenzie WN, Petroski GF. A randomized multi-arm repeated-measures prospective study of several modalities of portable oxygen delivery during assessment of functional exercise capacity. Respir Care 2009;54(3): 344-349. 